\title{
Uma história em quadrinhos para mobilizar as interações discursivas em uma sequência de ensino e aprendizagem de química
}

Jucilene Santana Santos uucilene1988@live.com https://orcid.org/0000-0003-0222-8749 Universidade Federal de Sergipe, São Cristóvão, Sergipe, Brasil

Filipe Silva de Oliveira oliveiradefs@gmail.com https://orcid.org/0000-0003-3963-1355 Universidade Federal de Sergipe, São Cristóvão, Sergipe, Brasil

Adjane da Costa Tourinho e Silva

adtourinho@terra.com.br

Universidade Federal de Sergipe, São Cristóvão, Sergipe, Brasil

\section{RESUMO}

O artigo apresenta uma discussão acerca das contribuições da aplicação de uma História em Quadrinhos (HQ), inserida em uma sequência de ensino e aprendizagem (SEA) de Química, para as interações discursivas e o engajamento dos alunos. A SEA foi aplicada, como oficina, para 27 alunos do primeiro ano do Ensino Médio de uma escola da rede pública de ensino. Os dados escritos, bem como as aulas registradas em vídeo, foram submetidos à análise por meio de categorias dispostas na literatura. Foram focalizados, na análise, os padrões de interação, os tipos de perguntas dos alunos e o seu engajamento, considerando-os como elementos relevantes para a aprendizagem, de acordo com uma perspectiva sociocultural de educação. A pesquisa justifica-se tendo-se em vista a importância de investimentos na compreensão do potencial de recursos didáticos no ensino de Ciências que favoreçam as interações que se desenvolvem no plano social da sala de aula. Os resultados apontam que a HQ aplicada ao longo da SEA contribuiu para fomentar as discussões em torno do tema proposto, "qualidade da água", por meio das quais foi possível verificar o engajamento dos alunos.

PALAVRAS-CHAVE: Histórias em Quadrinhos. Sequência de Ensino e Aprendizagem. Engajamento dos alunos. 


\section{AS HISTÓRIAS EM QUADRINHOS (HQS) E SUA INSERÇÃO NO CAMPO DA EDUCAÇÃO}

As histórias em quadrinhos (HQs) são uma forma de expressão da cultura humana. Como meio de comunicação em massa, surgiram na Europa e nos Estados Unidos no final do século XIX, ampliando-se, a partir da década de 1930, para praticamente todos os países do mundo (VERGUEIRO, 2005). A íntima relação entre palavras e imagens desenhadas em uma narrativa, além de seu caráter lúdico, é um dos motivos que levam este gênero textual ao consumo editorial.

Considerando a multiplicidade de meios de utilização das HQs no campo da educação, as pesquisas ao longo do último século intensificaram a divulgação de resultados que explicitam o quanto esta expressão artística tem o potencial favorecedor do processo de ensino e aprendizagem. Luyten (2011) argumenta que as HQs favorecem a formação de novas ideias a partir das suas infinitas possibilidades de exploração e utilização, que vão de situações imaginárias a situações vivenciadas no cotidiano das pessoas. As histórias em quadrinhos motivam à prática de muitas atividades relativas à cognição, dentre as quais se pode citar a linguagem escrita e a oralidade, de tal modo que se torna um incentivo à produção literária e artística dos alunos.

No Brasil, o interesse pelas HQs na educação cresceu nos últimos anos em virtude das orientações veiculadas pelos Parâmetros Curriculares Nacionais (PCNs) (BRASIL, 2002) que, a partir do incentivo oficial oferecido pela Lei de Diretrizes e Bases (LDB 9394/96) (BRASIL, 2005), permitiu aos quadrinhos tomar fôlego na educação formal, com professores de todos os níveis e modalidades (VERGUEIRO, 2004). A partir de 2006, as HQs foram inclusas no PNBE (Programa Nacional Biblioteca da Escola) que objetiva entre outras ações, distribuir HQs no Ensino Fundamental e Médio, juntamente com o apoio do FNDE (Fundo Nacional de Desenvolvimento da Educação).

Apesar de as HQs estarem sendo inseridas no contexto escolar, contando com o incentivo de programas governamentais, é de grande importância que os professores estejam preparados para sua utilização em sala de aula, pois as mesmas não podem ser vistas apenas como incentivo à leitura na perspectiva lúdica, e sim, como uma ferramenta capaz de contextualizar e construir conhecimentos. Assim, é recomendável que estudos se voltem às HQs de modo a compreender as suas potencialidades enquanto recurso didático, considerando as especificidades das diferentes áreas do conhecimento, a fim de favorecer a percepção dos professores sobre as possibilidades de seu uso em sala de aula.

\section{AS HQS E O ENSINO DE CIÊNCIAS}

Na pesquisa em ensino de Ciências, as HQs têm ganhado espaço sob enfoques variados, obtendo um aumento significativo nos últimos 5 anos (CAMARGO; RIVELINI-SILVA, 2017). Considerando o ensino de Química, Santos, Silva e Oliveira (2016) analisaram periódicos e eventos da área de Educação em Ciências verificando características das publicações que tratavam das HQs no período de 2005 a 2015. Os autores observaram que uma parte de tal produção 
relatava trabalhos que envolviam a inserção deste recurso didático em sequências de ensino e aprendizagem (SEAs), as quais eram analisadas avaliandose os lucros do processo, enquanto que, outra parte envolvia a análise de HQs em livros didáticos. Dos artigos que envolviam a inserção de HQs em SEAs, a maioria considerava a confecção de HQs pelos alunos, sendo que apenas uma menor quantidade envolvia a confecção de HQs pelos professores, que as utilizavam como instrumento de divulgação complementar à educação que formalmente desenvolviam.

Tais pesquisas evidenciam como as HQs se constituem em um instrumento didático eficaz, com potencial de fomentar o interesse e a autonomia dos alunos, favorecendo a aprendizagem de conceitos; incluso a isto está a motivação que é fator que salta nos resultados dos trabalhos. Neste sentido, a análise das contribuições das HQs nessas pesquisas, em sua maioria, foca no caráter motivacional deste recurso e na aprendizagem de conceitos específicos. Soares Neto, Pereira e Souza (2013) e Santos et al. (2014), por exemplo, avaliam como a própria estrutura dos quadrinhos com seu recurso de imagem e texto são relevantes no processo de construção do conhecimento. Em menor quantidade estão as pesquisas cujo foco das análises está na incorporação da linguagem científica pelos alunos. Inserem-se aí aquelas que consideram como as HQs favorecem a transição entre a linguagem cotidiana e a científica, bem como a linguagem virtual.

Camargo e Rivelini-Silva (2017) em uma pesquisa de revisão considerando trabalhos tratando de HQs no ensino de Ciências nos ENPEC e ENEQ nos últimos 12 anos mostram resultados semelhantes aos de Santos, Silva e Oliveira (2016). Todavia, apontam também trabalhos que discutem sobre as abordagens das HQs na formação docente. Os autores declaram que estudos que relatam o uso de materiais inéditos aparecem de maneira mais frequente quando comparados àqueles que se propõem à análise e/ou uso de materiais já disponíveis.

Apesar do crescente número de pesquisas que se voltam para a análise de HQs no ensino de Ciências e, de forma mais específica no ensino de Química, há uma carência de estudos que se voltem para análise das interações, discursos e linguagem frente aos demais, tendo em vista o uso deste recurso. Embora a maioria dos trabalhos destaque, de alguma forma, o engajamento dos alunos com as aulas e as interações que são desencadeadas com o uso das HQs, tais aspectos são, geralmente, considerados de forma secundária ou complementar, visto que a ênfase é na verificação do produto, expresso no alcance das concepções científicas pelos alunos, e não nas interações discursivas que se desenvolvem entre os sujeitos de sala de aula gerando espaço para o processo de construção de novas ideias. Além disso, percebe-se que não há artigos que discutam sobre HQs voltadas para a interatividade, ou seja, aquelas em que os alunos preenchem espaços correspondentes às falas das personagens da história, interagindo com elas.

A ênfase nas interações que se desenvolvem no plano social da sala de aula a fim de que se compreenda o processo de construção de novos significados que nestes espaços se desenvolvem tem se expressado de forma significativa na pesquisa na Educação em Ciências desde a década de 1990. A psicologia histórico-cultural tem sido utilizada como referencial teórico que fundamenta os 
estudos sobre as interações discursivas neste campo. Consideramos relevante investir mais nessa perspectiva, tendo como foco as HQs.

\section{A PROPOSTA DESTE TRABALHO}

Interessamo-nos, portanto, em produzir uma HQ com o objetivo de favorecer o desenvolvimento das interações discursivas e o engajamento dos alunos em uma sequência de ensino e aprendizagem de Química. Nessa perspectiva, a $\mathrm{HQ}$ foi elaborada de modo a reservar espaços em branco para as falas dos alunos, as quais consistiam em respostas às questões propostas. Assim, antes de as interações se pronunciarem por meio das discussões entre alunos e professor, elas já se iniciavam na relação entre os alunos e as personagens da $\mathrm{HQ}$, de forma a possibilitar que os discentes se detivessem mais na reflexão acerca de suas próprias ideias e daquelas mobilizadas pela leitura, expressando-as por escrito.

Ao considerarmos o potencial da $\mathrm{HQ}$ para fomentar as interações, assumimos que a possibilidade de os alunos expressarem suas ideias na HQ é uma característica que reforça a interatividade entre alunos e personagens e, consequentemente, entre alunos e professor, em um momento posterior.

Tal aspecto da HQ elaborada faz com que, de certa forma, sua proposta se aproxime do caráter interativo discutido por Levy (1999), ao tratar de cibercultura. O autor argumenta que a interatividade de um determinado produto, ou de uma mídia, relaciona-se ao grau de capacidade que um receptor tem de participar ativamente na troca de informação com o emissor, de modo a chegar a inverter tais papeis. Quanto maior a possibilidade de reapropriação e de recombinação material da mensagem por um receptor em um determinado produto, maior o seu grau de interatividade. Com efeito, apesar de a HQ discutida neste artigo não se tratar de um produto digital que possibilite uma inversão de papeis (emissor- receptor na acepção de Levy (idem)), ela mobiliza os alunos a interagirem com os personagens expondo as suas ideias em função daquelas disponibilizadas no texto.

A HQ, com tais características, foi o eixo central da Sequência de Ensino e Aprendizagem (SEA) planejada. Na perspectiva de percepção das HQs como elemento favorecedor das interações em sala de aula desenvolvemos a nossa pesquisa, a qual buscou caracterizar os padrões estruturais de interação e o engajamento dos alunos apresentados ao longo de uma sequência de ensino e aprendizagem (SEA) de Química, desenvolvida em torno de uma HQ que teve por tema a qualidade da água.

A SEA com o uso da HQ foi desenvolvida em forma de oficina, a qual foi destinada a alunos do primeiro ano do Ensino Médio de uma escola pública da cidade de Aracaju - SE. Participaram da oficina 27 alunos na faixa etária de 14 a 17 anos. Os participantes leram e responderam às questões propostas na $\mathrm{HQ}$, formando duplas ou trios. Ao todo, 14 exemplares da HQ foram respondidos.

A análise foi desenvolvida mediante as categorias voltadas para as interações discursivas propostas por Mortimer e Scott (2003). As perguntas elaboradas pelos alunos foram também analisadas por meio de categorias propostas por Aguiar Junior, Mortimer e Scott (2006), com base na discussão apresentada por Candela 
(1999) sobre a estrutura do discurso de salas de aula de ciências. Entendemos que a frequência e os tipos de pergunta apresentados contribuem para expressar o engajamento dos alunos ao longo da SEA.

\section{ASPECTOS TEÓRICO-METODOLÓGICOS}

Inicialmente, apresentaremos as categorias analíticas que utilizamos para caracterização dos aspectos interacionais relacionados à aplicação da HQ para, em seguida, discutirmos sobre os procedimentos de produção, tratamento e análise dos dados.

\section{AS CATEGORIAS ANALITICAS}

\section{Os Padrões De Interação}

Os padrões de interação, segundo Silva (2008), referem-se a modos de alternância de turnos de fala entre alunos e professor ou mesmo entre alunos. Para dar conta da diversidade de situações e padrões apontados na literatura, Mortimer et al. (2007) definiram um conjunto de 26 categorias que codificam os turnos e identificam os padrões de interação. Tomando por base o trabalho de Mehan (1979), foram definidos 4 tipos de iniciação, aplicáveis tanto às iniciações do professor quanto às dos estudantes:

1. iniciação de escolha (le): são aquelas que demandam ao respondente que concorde ou discorde com uma afirmação feita pelo interrogador;

2. iniciação de produto (Ip): são aquelas que demandam ao respondente uma resposta factual como um nome, um lugar, uma data, uma cor;

3. iniciação de processo (Ipc): são aquelas que demandam a opinião ou interpretação do respondente;

4. iniciação de metaprocesso ( $(\mathrm{mpc})$ : são aquelas que demandam aos estudantes que sejam reflexivos sobre o processo de estabelecer conexões entre elicitações e respostas, refletindo sobre as bases de seu pensamento.

Correspondendo a esses 4 tipos de iniciação, existem também 4 tipos de resposta. Esse conjunto de 4 categorias, combinado com a possibilidade de uma iniciação ou uma resposta ter sido enunciada pelo professor ou por um estudante, dá origem a 16 diferentes categorias.

Além dessas 16 categorias, são definidas outras, dentre as quais destacamos 3:

17. avaliação, pelo professor (A): um turno de fala que é usado para fechar tanto uma sequência triádica ${ }^{1}$ quanto uma cadeia fechada de interações²; 
18. feedback ou prosseguimento (F), normalmente pelo professor: um turno de fala que demanda uma elaboração adicional do aluno, possibilitando prosseguimento à sua fala. Normalmente dá origem a cadeias de interação;

19. síntese final da interação, pelo professor (Sf): quando o professor, geralmente após fechar uma sequência com uma avaliação, produz um enunciado final para sintetizar o conteúdo do enunciado que foi produzido na cadeia de interação.

\section{OS TIPOS DE PERGUNTAS DOS ALUNOS}

Realizamos uma análise dos tipos de perguntas propostas pelos alunos verificando as conexões que o professor faz diante destas. Para isso, tomamos como referência as categorias propostas por Aguiar Junior, Mortimer e Scott (2006) com base na discussão apresentada por Antônia Candela (1999). Os autores propõem três categorias: perguntas de esclarecimento ou extensão, perguntas de extrapolação e perguntas de contestação, as quais estão representadas no Quadro 1 que segue:

Quadro 1 - Tipos de perguntas dos estudantes

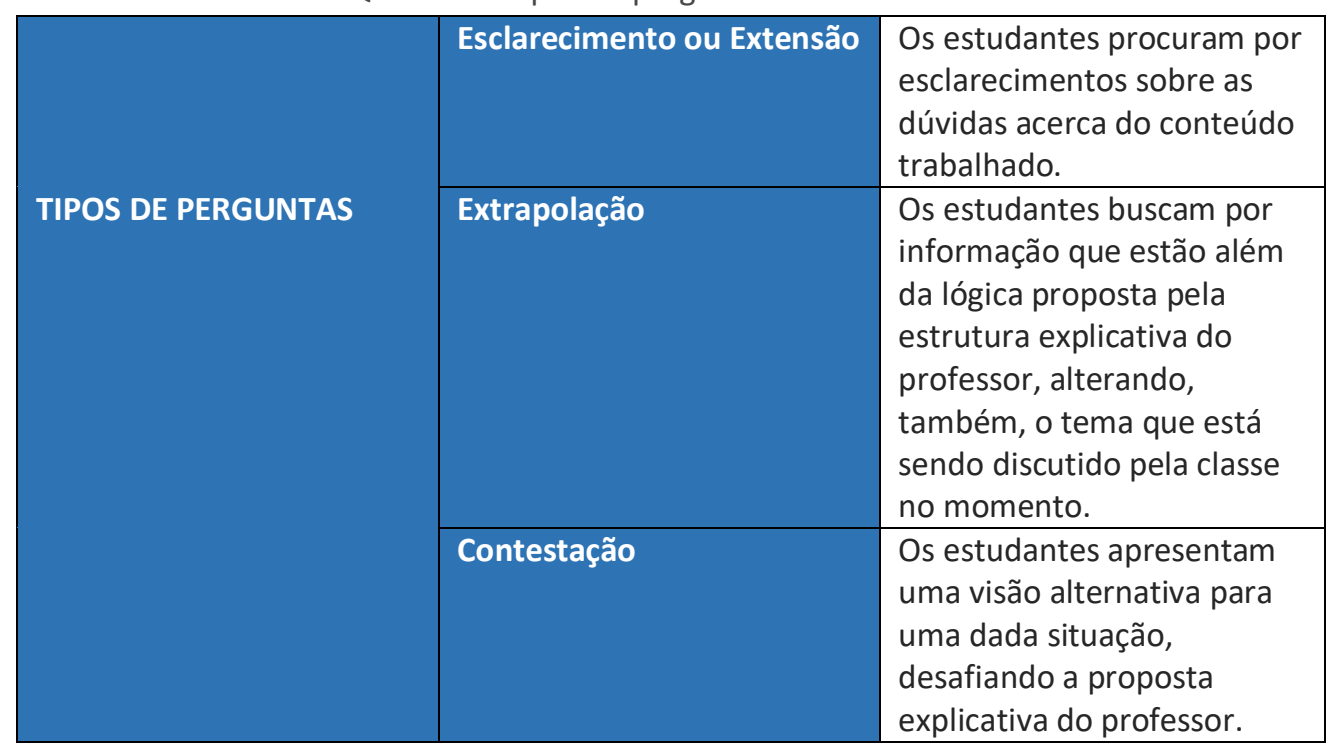

Fonte: Adaptado de Aguiar Junior, Mortimer e Scott (2006, p. 2).

\section{PRODUÇÃO, TRATAMENTO E ANÁLISE DOS DADOS}

Os dados foram gerados durante o desenvolvimento da SEA e aplicação da $H Q^{3}$. Por meio desta última, foram obtidos os dados escritos referentes às respostas dos alunos registradas nos balões com espaços vazios. Além disso, as aulas foram registradas em áudio e vídeo, de modo a capturar as interações entre professora e turma, bem como entre os alunos de duplas específicas tomadas para análise ao longo da SEA.

Neste artigo, o foco principal está na análise dos registros escritos, os quais nos permitem relacionar o perfil da $\mathrm{HQ}$ com as perguntas e respostas 
apresentadas pelos alunos. Todavia, a fim de promover a percepção sobre como a interação dos alunos com tal material didático prosseguia e avançava nas discussões da professora com toda a turma, apresentaremos uma análise de excertos de algumas dessas discussões nos diferentes encontros da SEA.

Os registros em áudio e vídeo foram transcritos e submetidos à análise por meio das categorias descritas na seção anterior, da mesma forma como ocorreu com os dados escritos. A percepção do engajamento dos alunos foi promovida tendo-se em vista uma comparação entre o tempo em que estes se envolviam na temática proposta para cada aula e o tempo em que abordavam outros temas. A cada encontro, uma nova dupla ou trio de alunos era tomada como referência para a percepção do engajamento, tendo como recurso de registro o gravador. Além disso, a quantidade e os tipos de pergunta que os alunos propuseram ao logo da SEA serviram de indicativo de engajamento.

A seguir, apresentamos os principais aspectos da SEA em que se inseriu a $\mathrm{HQ}$ para, a partir daí, centrar na discussão sobre este material.

\section{A SEQUÊNCIA DE ENSINO E APRENDIZAGEM (SEA) EM QUE SE INSERE A HQ}

A sequência de ensino e aprendizagem, desenvolvida em torno da $\mathrm{HQ}$, compôs-se de doze (12) aulas. Tais aulas foram desenvolvidas em quatro (4) encontros, atendendo aos "Três Momentos Pedagógicos (3MP)" propostos por Delizoicov, Angotti e Pernambuco (2002). De acordo com os autores, o primeiro momento consiste em problematizar o conhecimento; este vem seguido de um segundo, o qual envolve uma organização dos conhecimentos e, por fim, tem-se o terceiro, que consiste na aplicação do conhecimento.

O primeiro momento, denominado de problematização inicial, define-se pela exposição de um problema científico ou social que se faça presente no cotidiano dos discentes e que por meio do qual seja possível estabelecer uma relação com o conhecimento de forma contextualizada; tal problema deverá permear por toda a SEA, de modo que os alunos percebam que precisam aprender novos conhecimentos para se tornarem capazes de interpretar, compreender e explicar a situação problematizada. Em nossa SEA, esse primeiro momento envolveu as aulas 1,2 e 3.

O questionamento inicial proposto aos alunos foi: que características deve ter a água para ser considerada boa para o consumo humano? A discussão que se desencadeou a partir de tal questão permitiu explorar as concepções prévias dos alunos, as quais haviam sido expressas em questionário (pré-teste), além de fomentar a necessidade de aquisição de outros conhecimentos que eles ainda não detinham. Desse modo, ao longo do desenvolvimento da SEA, em nossa pesquisa, conceitos anteriores foram retomados e reelaborados, tais como as concepções de substâncias, mistura de substâncias e propriedades organolépticas, e outros novos foram construídos, como as concepções de água potável e água mineral comercializada, os conceitos de acidez, basicidade e pH.

No segundo momento, de organização dos conhecimentos, pretende-se que estes sejam construídos e sistematizados, criando-se uma sequência lógica entre eles, o que gera uma capacidade de reorganização conceitual que promove a base para o terceiro momento envolvendo a aplicação dos conhecimentos 
elaborados. Inicia-se, portanto, neste segundo momento do roteiro pedagógico, o estudo sistemático do conteúdo programático. Tal momento correspondeu às aulas 4,5 e 6 . Nestas aulas, partiu-se das concepções anteriores dos alunos, voltando-se o olhar para o caso da água que a população consome: Trata-se de uma substância pura ou uma mistura de substâncias? Quando a água pode ser considerada adequada ao consumo humano? Nessa direção, foram abordados os conceitos de água potável e água mineral comercial, bem como os parâmetros gerais de potabilidade da água. Aprofundando, foram introduzidos os conceitos de ácidos e bases, bem como o de $\mathrm{pH}$.

No último momento pedagógico, os alunos têm a oportunidade de aplicar os conhecimentos que foram problematizados e organizados. A perspectiva investigada durante este momento pode ser concebida como "reducionista ou ampliada" (AULER, 2003). Nesse sentido, pode-se ampliar o quadro das informações adquiridas ou ainda abranger conteúdo distinto da situação original (abstraída do cotidiano do aluno), mas decorrente da própria aplicação do conhecimento. Torna-se, assim, possível ampliar o conteúdo programático, extrapolando-o para uma esfera que transcende o cotidiano do aluno. Tal momento correspondeu às aulas $7,8,9,10,11$ e 12. Nessas aulas, os alunos analisaram os rótulos de águas minerais comerciais, verificando a composição e o $\mathrm{pH}$ de cada uma delas e realizaram uma atividade investigativa envolvendo experimento em que, por meio de indicadores ácido-base (papel indicador de $\mathrm{pH}$ e extrato de repolho-roxo), verificaram o nível de acidez de algumas marcas de águas minerais e de amostras de água potável, como também de refrigerantes e sucos de caixa. Ainda nessa fase, foi desenvolvida uma discussão final avaliando o caminho percorrido ao longo da SEA, ou seja, as ideias elaboradas, as suas contribuições para que fossem elaboradas respostas para a questão introduzida inicialmente e, sobretudo, para a vida dos alunos, bem como o uso da HQ como material didático prioritário na sequência.

Conforme veremos, a HQ fez parte de todas as aulas. Por meio deste recurso, informações foram disponibilizadas, conceitos foram retomados e introduzidos, questionamentos foram propostos e, por parte dos alunos, respostas e questionamentos foram apresentados por meio dos balões com espaços vazios para tal fim. Nesse sentido, a dinâmica das aulas envolvia sempre, em diferentes momentos, a leitura da $\mathrm{HQ}$ em grupos, seguida de discussão com toda a turma guiada pela professora.

O Quadro 2 apresenta os encontros com seus respectivos objetivos, estratégias didáticas e número de aulas, considerando-se ainda a relação destas últimas como os momentos pedagógicos discutidos. Ele sintetiza a estrutura da SEA explicitando o uso da HQ nas aulas.

A SEA, elaborada em torno da $\mathrm{HQ}$, foi analisada e sofreu alguns ajustes tendo em vista discussões postas na literatura acerca da elaboração e análise de sequências didáticas (também referidas como sequências de ensino e aprendizagem), sobretudo as de caráter investigativo. Não é nosso objetivo, neste artigo, discutir a fundo potencialidades e limitações da nossa SEA em função de uma variedade de critérios, visto que o foco de nossas atenções é a análise de suas contribuições (mais precisamente da HQ) para as interações entre os sujeitos de sala de aula e o engajamento dos alunos. Todavia, torna-se 
relevante ressaltarmos aqui algumas de suas características, de acordo com aspectos pontuados em análises de sequências didáticas.

Guimarães e Giordan (2012) e Bego, Alves e Giordan (2019) apresentam elementos para tal tarefa. Esses autores propõem 4 (quatro) dimensões de análise, sendo elas: estrutura e organização; problematização; conteúdos e conceitos; e metodologias de ensino e avaliação.

Quadro 2 - Síntese estrutural da SEA

\begin{tabular}{|l|l|l|l|}
\hline \multicolumn{2}{|c|}{ Objetivo geral: Possibilitar a compreensão de características físico-químicas da água } \\
adequada ao consumo humano, bem como fomentar habilidades discursivas e de \\
\hline leitura diante de questões sociais e científicas relativas ao tema \\
\hline
\end{tabular}




\begin{tabular}{|l|l|l|l|l|}
\hline \multicolumn{3}{|l|}{ Objetivo geral: Possibilitar a compreensão de características físico-químicas da água } \\
\multicolumn{2}{l|}{ adequada ao consumo humano, bem como fomentar habilidades discursivas e de } \\
leitura diante de questões sociais e científicas relativas ao tema
\end{tabular}

Fonte: Autoria própria (2017).

Com relação à primeira dimensão (estrutura e organização), salientamos que nossa SEA se organizou em torno de uma estrutura ancorada em uma proposta teórica consistente, com aulas planejadas de acordo com objetivos específicos claros, voltados às habilidades requeridas aos alunos e em consonância com o objetivo mais amplo (ver Quadro 2).

A segunda dimensão refere-se à problematização. Tal aspecto tem sido recorrentemente enfatizado na literatura sobre sequências didáticas. Ainda que uma sequência didática não tenha caráter predominantemente investigativo, uma fase ou etapa de problematização é geralmente proposta logo em seu início como forma de se introduzir o eixo estruturador da sequência, bem como mobilizar os alunos ao engajamento (BEGO; ALVES; GIORDAN, 2019; CARVALHO, 2013; DELIZOICOV; ANGOTTI; PERNAMBUCO, 2002; GUIMARÃES; GIORDAN, 2012; MORTIMER; SCOTT, 2003). Em nossa SEA, as aulas iniciais são destinadas à problematização, ao tempo em que as concepções prévias dos alunos são exploradas. O problema proposto expressa-se por meio de uma questão sociocientífica, a qual se desdobra em outras questões que vão se configurando ao longo da $\mathrm{HQ}$.

No tocante aos conteúdos e conceitos, Bego, Alves e Giordan (2019) observam que estes não devem ser os únicos elementos levados em conta em 
uma avaliação, a qual deve ser vista de uma perspectiva mais ampla, englobando capacidades cognitivas e demais capacidades. Em nossa SEA, as demandas para os alunos expressarem seus pontos de vista por meio de repostas às questões propostas, bem como pela apresentação de perguntas, tanto orais quanto escritas, favorecem o desenvolvimento de habilidades discursivas, aliadas ao aprimoramento da leitura. Isso possibilita uma avaliação processual, afastando-se de uma perspectiva tecnicista, em que a avaliação ocorre apenas ao final do processo. Além disso, as atividades investigativas envolvendo experimentos possibilitam o desenvolvimento de práticas epistêmicas (KELLY, 2008).

Por fim, com relação ao aspecto Metodologias de ensino e avaliação, em consonância com a discussão dos autores (idem), levamos em conta, na avaliação, a evolução conceitual, bem como a capacidade dos alunos em se posicionarem expressando seus pontos de vista e questionamentos, os quais eram fomentados pela leitura da $\mathrm{HQ}$. As estratégias didáticas envolveram leitura e discussão da $H Q$, exposições pela professora para fechamento de ideias e realização de experimento (proposto na $\mathrm{HQ}$ ) na perspectiva investigativa.

A HQ - "A água nossa de cada dia"

A HQ intitulada "A água nossa de cada dia" narra uma história que se passa num ambiente escolar. Ela foi desenvolvida ao longo da pesquisa de mestrado da primeira autora deste artigo. Compõe-se de 20 páginas, tendo como principais personagens envolvidos a professora Jucy e os alunos Filipe e Rafaela.

O contexto da narrativa envolve uma série de diálogos entre Filipe e Rafaela e entre eles e a professora, ao longo das aulas. O personagem Filipe é um pouco disperso quanto às atividades da escola; Rafaela busca estimulá-lo a participar das aulas, argumentando que o que se aprende nas aulas de Química é bastante interessante e útil. Ao longo da narrativa, Filipe torna-se cada vez mais engajado. A HQ ${ }^{4}$ foi confeccionada por meio do software pixton e do programa CorelDraw. As imagens das personagens principais foram obtidas a partir de uma caricaturização de fotos de pessoas reais, alunos do grupo de pesquisa que colaboraram com o processo de confecção. No texto que segue, apresentamos alguns exemplos de partes da HQ.

Figura 1 - Capa e interior da HQ

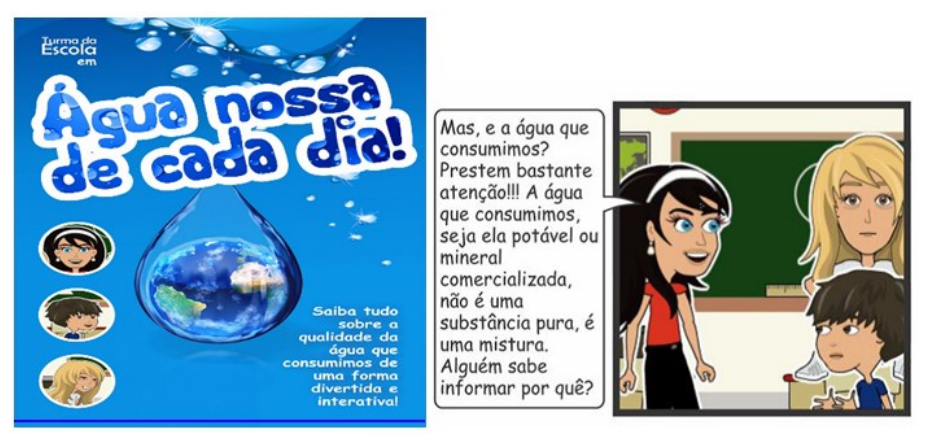

Fonte: Autoria própria (2017).

$\mathrm{Na} H Q$, a professora Jucy desenvolve suas aulas gerando uma discussão sobre a qualidade da água consumida pelos alunos. A partir do diálogo entre 
professora e alunos da $\mathrm{HQ}$, os alunos da sala de aula real são convidados a refletir sobre a qualidade da água para o consumo humano. Filipe e Rafaela (personagens) também geram espaço para interação com os alunos reais. Desse modo, ao tempo em que os alunos reais são levados a uma interpretação da HQ, são questionados em vários momentos pelas personagens, podendo então escrever seus pontos de vista nos balões em branco. Tal estrutura permite que os alunos reais interajam com os alunos da HQ e possam ser co-autores da história.

A interatividade expressa na $\mathrm{HQ}$, como discutida na introdução deste artigo, está na relação de diálogo dos personagens com o leitor e na possibilidade de os alunos (reais) dialogarem por meio dos balões em branco expressando suas ideias.

A interface mais expressiva entre a sala de aula da $\mathrm{HQ}$ e a sala de aula real é a professora Jucy, ou seja, a personagem da HQ representa a própria professora real que desenvolve a SEA. Vejamos a ilustração que segue:

Figura 2 - Trecho do interior da HQ

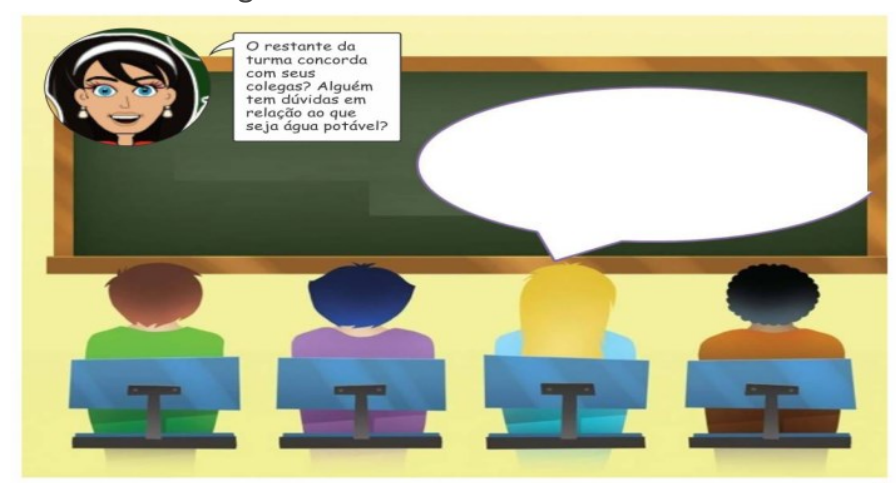

Fonte: Autoria própria (2017).

\section{O Perfil Interativo da HQ}

Na Tabela 1, apresentamos um perfil da $\mathrm{HQ}$ considerando os padrões de interação que se buscou promover. As informações contidas na tabela dizem respeito às perguntas propostas pela professora-personagem e pelos alunospersonagens, Filipe e Rafaela, considerando sua classificação quanto aos padrões de interação. Explicitando este perfil, buscamos expressar o potencial da HQ para promover as interações discursivas quando utilizada como material didático em sala de aula.

Tabela 1 - Tipos de Iniciação (perguntas) da HQ

\begin{tabular}{l|l|l|l}
$\begin{array}{c}\text { Tipo de } \\
\text { iniciação }\end{array}$ & \multicolumn{1}{|c|}{ Exemplos } & $\begin{array}{c}\text { Quantidade } \\
\text { Absoluta }\end{array}$ & $\begin{array}{l}\text { Quantidade } \\
\text { Percentual } \\
\text { (\%) }\end{array}$ \\
\hline \multirow{3}{*}{ Escolha } & $\begin{array}{l}\text { O restante da turma concorda com } \\
\text { seus colegas? }\end{array}$ & \multirow{2}{*}{13} & 37,14 \\
\cline { 2 - 4 } & $\begin{array}{l}\text { E a água potável, pode ser considerada } \\
\text { mineral? }\end{array}$ & \multirow{2}{*}{22,86} \\
\hline \multirow{2}{*}{ Produto } & $\begin{array}{l}\text { Alguém pode dar exemplos desse tipo } \\
\text { de material? ((sistema homogêneo)) }\end{array}$ & 08 & 2 \\
\cline { 2 - 4 } & Qual o pH ideal de uma água para & & \\
\hline
\end{tabular}




\begin{tabular}{l|l|l|l}
\hline $\begin{array}{c}\text { Tipo de } \\
\text { iniciação }\end{array}$ & \multicolumn{1}{|c|}{ Exemplos } & $\begin{array}{c}\text { Quantidade } \\
\text { Absoluta }\end{array}$ & $\begin{array}{c}\text { Quantidade } \\
\text { Percentual } \\
\text { (\%) }\end{array}$ \\
\hline & consumo humano? & & \\
\hline \multirow{2}{*}{ Processo } & $\begin{array}{l}\text { As propriedades organolépticas são } \\
\text { importantes na avaliação da qualidade } \\
\text { da água? Justifique. }\end{array}$ & \multirow{2}{*}{14} & \multirow{2}{*}{40,00} \\
\cline { 2 - 3 } & $\begin{array}{l}\text { E aí pessoal, o que vocês conseguiram } \\
\text { entender do experimento? }\end{array}$ & 35 & 100 \\
\hline Total & & &
\end{tabular}

Fonte: Autoria própria (2017).

A HQ envolveu ao todo 35 iniciações (perguntas), dentre as quais 8 (22,86\%) são de produto, $13(37,14 \%)$ são de escolha e $14(40,00 \%)$ são de processo. É importante ressaltar que a maioria das perguntas de escolha são introdutórias para as perguntas de processo, ou seja, elas se prestam a apresentar tal tipo de pergunta. Vejamos:

Professora Jucy: Mas, e aí? Podemos afirmar que a água mineral comercial, é uma água potável? O que vocês acham?

Professora Jucy: O tratamento pelo qual a água passa pode mudar as suas propriedades organolépticas? Por quê?

As perguntas de maior frequência na $\mathrm{HQ}$ foram as de processo $(40,00 \%)$. Tal elicitação, de acordo com Mehan (1979), demanda do estudante que ele expresse suas opiniões para quem o questiona. O predomínio deste tipo de elicitação/pergunta na $\mathrm{HQ}$, demonstra que este material didático procura conduzir os alunos a elaborarem mais suas ideias em torno dos fenômenos analisados, favorecendo uma maior reflexão sobre estes. Tal processo possibilita a internalização de formas de descrição e explicação de fenômenos e conceitos científicos com argumentações cada vez mais complexas pelos alunos (AGUIAR JUNIOR; MORTIMER, 2005).

Seguindo as perguntas de processo, vem as de escolha. Estas demandam pouca atividade reflexiva dos alunos, estando com $37,14 \%$ de presença na $\mathrm{HQ}$. Elas requerem respostas geralmente curtas, em torno do sim ou do não, de modo que não possibilitam o conhecimento profundo sobre as concepções dos alunos. Conforme comentamos, uma boa parte das questões de escolha na HQ prestouse a introduzir perguntas de processo.

O terceiro tipo de pergunta, em incidência, foi a de produto $(22,86 \%)$. As iniciações de produto requerem respostas factuais, como o nome de uma substância, uma característica específica de um evento ou objeto etc. $\mathrm{Na}$ confecção da $\mathrm{HQ}$, buscamos diminuir a quantidade de perguntas de produto, priorizando uma maior interpretação dos alunos frente aos questionamentos do tipo processo. Todavia, torna-se importante esse tipo de pergunta, dado que em várias situações é fundamental que sejam pontuados aspectos descritivos dos fenômenos analisados.

Ressaltamos que, apesar de na HQ não se materializarem as cadeias de interação, visto que a professora dos quadrinhos não dá retorno às respostas apresentadas pelos alunos reais, isso acontece quando as respostas dos alunos 
são retomadas na discussão que se faz com toda a turma nos momentos após as leituras da HQ.

\section{RESULTADOS E DISCUSSÃO}

\section{AS RESPOSTAS DOS ALUNOS NA HQ E AS INTERAÇÕES EM SALA DE AULA}

Iniciamos essa discussão considerando os tipos de respostas apresentadas pelos alunos às questões propostas na $\mathrm{HQ}$. Isso é feito tendo-se em vista que as respostas que se apresentam a partir de uma elicitação qualquer não seguem necessariamente o tipo de tal elicitação, ou seja, da pergunta proposta. Todavia, em nosso caso, praticamente todas as respostas foram do mesmo tipo da pergunta, com uma pequena exceção, em uma das perguntas de escolha. Salvo isso, as perguntas de processo e produto foram seguidas, respectivamente, por respostas de processo e produto.

No caso das perguntas de escolha, a exceção correspondeu ao caso em que, apesar de uma delas não ter vindo seguida por uma pergunta de processo, foi entendida como tal por 4 grupos de alunos, ou seja, estes apresentaram os porquês de suas respostas de escolha, mesmo sem terem sido solicitados a fazêlo. O que deve ser ressaltado, todavia, é que algumas perguntas ficaram com o espaço para resposta em branco ou foram respondidas parcialmente na $\mathrm{HQ}$, embora fossem respondidas quando colocadas em discussão com toda a turma.

Considerando-se que, em cada $\mathrm{HQ}$ há 35 perguntas, as quais potencialmente geram 35 respostas, e que foram 14 exemplares respondidos, teríamos no máximo 490 respostas. Obtivemos, todavia, o total de 335 respostas. Ficaram então, sem respostas, 155 questões, o que dá uma média de 11 questões em branco para cada exemplar de HQ. Isso pode ser entendido, levando-se em conta que a frequência dos alunos não foi de $100 \%$ em todos os encontros, o que é compreensível, sobretudo, pelo fato de a oficina ter sido realizada em turno oposto ao das aulas regulares.

Abaixo apresentamos a Tabela 2, a qual apresenta os valores absolutos e percentuais de frequência para cada tipo de resposta dos alunos.

Tabela 2 - Percentuais de frequência para os tipos de respostas dos alunos

\begin{tabular}{lll} 
Tipos de respostas & Números absolutos & Percentuais (\%) \\
\hline Escolha & 121 & 36,12 \\
Produto & 85 & 25,37 \\
Processo & 129 & 38,51 \\
TOTAL & 335 & 100,00 \\
\hline
\end{tabular}

Fonte: Autoria própria (2017).

A opção por um maior percentual de perguntas de processo na $\mathrm{HQ}$, as quais geralmente vinham precedidas por perguntas de escolhas, teve um efeito positivo, pois o percentual referente às respostas de processo também foi mais alto entre os demais. Isso informa que o espaço gerado para que os alunos expressassem suas ideias por meio de enunciados completos foi bem usufruído, favorecendo tanto a reflexão sobre as ideias propostas, quanto a discussão em sala de aula que seguia as leituras dos alunos. 
Abaixo, apresentamos alguns excertos da $\mathrm{HQ}$ com respostas de alunos:

Figura 3 - Trechos da HQ com resposta dos alunos

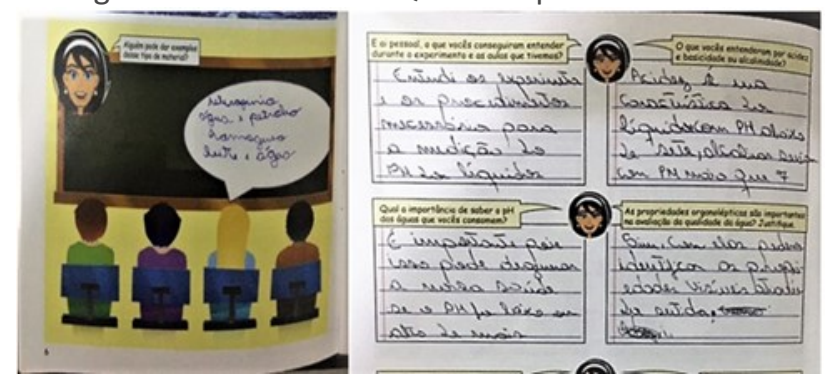

Fonte: Autoria própria (2017).

Em cada aula em que a HQ era utilizada, após uma apresentação inicial pela professora, os alunos eram solicitados a lerem, em duplas ou trios, a HQ para, em seguida, participarem de uma discussão com toda a turma guiada pela professora. Em tal discussão, as ideias apresentadas pelos alunos na HQ eram retomadas de modo que a aula se desenvolvesse. Nesse sentido, a professora explorava as concepções dos alunos, introduzia novas ideias, buscava conduzir, por meio de cadeias de interação, os pontos de vista dos alunos às concepções cientificamente corretas e assim por diante, a depender do que se pretendia em cada aula. Portanto, ao longo dessas interações no plano social da sala de aula, os alunos passavam também a apresentar os seus questionamentos. Antes, porém, de discutirmos sobre tais questionamentos vamos nos deter nas interações que se desencadeavam em sala de aula nos momentos posteriores às leituras da HQ.

Apresentamos dois episódios que correspondem a dois movimentos discursivos distintos da professora. No primeiro, a professora atua com um discurso de autoridade a fim de conduzir as concepções dos alunos àquelas cientificamente aceitas. No segundo a professora abre espaço para os pontos de vista dos alunos, possibilitando-se dessa forma, uma melhor compreensão de suas ideias, bem como o surgimento de perguntas que são interpretadas de acordo com as categorias propostas por Aguiar Junior, Mortimer e Scott (2006).

O excerto que se apresenta abaixo é parte do Episódio 3, do Encontro 1. Nele, é possível perceber como a Profa Jucy considera as concepções dos alunos para ir retomando/introduzindo novas ideias. Desta forma, ela parte das concepções dos alunos para retomar/introduzir o conceito de propriedades organolépticas e sua relação com a qualidade da água. A questão em pauta decorre daquela presente na $\mathrm{HQ}$, a qual é retomada em discussão com toda a turma.

Quadro 3 - Propriedades organolépticas da água consumida

\begin{tabular}{|l|l|}
\hline Transcrições & $\begin{array}{l}\text { Padrões de } \\
\text { interação }\end{array}$ \\
\hline Prof: Então pessoal! O que vocês acham que seria uma água limpa? & Ipd \\
\hline Als: Sem sujeira, transparente. & Rpd \\
\hline $\begin{array}{l}\text { Prof: É por aí. A água para ser considerada limpa seria uma água } \\
\text { isenta de contaminações químicas e microbiológicas, que acabam } \\
\text { alterando seu odor e sabor. }\end{array}$ & $\mathrm{A}$ \\
\hline $\begin{array}{l}\text { Prof: Por exemplo a água que chega em nossas residências, pode ser } \\
\text { considerada uma água com essas propriedades? }\end{array}$ & les \\
\hline
\end{tabular}




\begin{tabular}{|l|l|}
\hline Transcrições & $\begin{array}{l}\text { Padrões de } \\
\text { interação }\end{array}$ \\
\hline $\begin{array}{l}\text { Al1:Depende professora! A água da minha casa às vezes chega } \\
\text { cristalina, sem cheiro, mas com sabor de ferro! }\end{array}$ & Rpd \\
\hline Al2: Também já percebi isso na água da escola. & Rpd \\
\hline $\begin{array}{l}\text { Prof: Pessoal essas características identificadas por vocês na água } \\
\text { potável de casa, como também da escola, podem ser chamadas de } \\
\text { propriedades organolépticas. Estas propriedades se referem ao } \\
\text { sabor, a cor e o odor presentes nestas águas (...). }\end{array}$ & Sf \\
\hline
\end{tabular}

Fonte: Autoria própria (2017).

Os quadros 4 e 5, apresentam transcrições que são parte do Episódio 10, do Encontro 4. Neles, é possível perceber como os alunos passam a apresentar questões tendo-se em vista a discussão desenvolvida.

Quadro 4 - pH e qualidade da água

\begin{tabular}{|l|l|}
\hline Transcrições & $\begin{array}{l}\text { Padrões de } \\
\text { interação }\end{array}$ \\
\hline $\begin{array}{l}\text { Prof: Pessoal. Vocês, ao analisarem os rótulos, conseguiram identificar } \\
\text { diferenças nos valores de pH? }\end{array}$ & les \\
\hline Al1: Sim & Res \\
\hline Al2: Consegui ver que o pH muda a depender da marca da água mineral. & Rpd \\
\hline $\begin{array}{l}\text { Al4: Professora, comparando com a escala de pH, eu percebi que } \\
\text { algumas marcas dessas águas são muito ácidas por terem pH muito } \\
\text { baixos. Então não é uma água muito boa para nossa saúde né? }\end{array}$ & Rpc/laes \\
\hline $\begin{array}{l}\text { Al3: Pelo o que eu verifiquei apenas } 2 \text { marcas dessas águas minerais se } \\
\text { aproximam de uma água neutra. }\end{array}$ & $\mathrm{Rpc}$ \\
\hline $\begin{array}{l}\text { Prof: Pessoal, de acordo com a escala de pH, valores abaixo de 7,0 } \\
\text { caracterizam meio ácido, valores acima de } 7 \text { caracterizam meio básico. } \\
\text { Será possível encontrar uma água neutra? }\end{array}$ & $\mathrm{Sf} / \mathrm{les}$ \\
\hline
\end{tabular}

Fonte: Autoria própria (2017).

Quadro 5-pH e qualidade da água - perguntas dos alunos

\begin{tabular}{|l|l|}
\hline Transcrições da fala & $\begin{array}{l}\text { Tipos de perguntas dos } \\
\text { Estudantes }\end{array}$ \\
\cline { 1 - 2 } $\begin{array}{l}\text { Al2: Professora quando a gente fez o experimento de } \\
\text { verificação de pH, verificamos que a água da torneira tem pH } \\
\text { menos ácido do que algumas marcas de águas minerais } \\
\text { comerciais, então posso beber sem medo a água da torneira? }\end{array}$ & \\
\cline { 1 - 1 } $\begin{array}{l}\text { Prof: Toda água que chega nas torneiras passam por estações } \\
\text { de tratamento. Analisamos no experimento apenas um fator } \\
\text { na qualidade da água que foi o pH, mas, como vimos existem } \\
\text { outros fatores que podem influenciar na qualidade da água } \\
\text { para consumo humano... se tratando de pH constatamos que } \\
\text { a água da torneira é melhor para nossa saúde. }\end{array}$ & \multirow{2}{*}{$\begin{array}{l}\text { Pextensão de } \\
\text { ext3: Professora a água poluída é a mesma coisa da água } \\
\text { contaminada? }\end{array}$} \\
\cline { 1 - 2 } Prof: Não.
\end{tabular}

Fonte: Autoria própria (2017). 


\section{AS PERGUNTAS DOS ALUNOS}

As perguntas apresentadas pelos alunos, ao longo da discussão com toda a turma, foram de dois tipos: perguntas de esclarecimento ou extensão e, em menor grau, perguntas de extrapolação. (AGUIAR JUNIOR; MORTIMER; SCOTT, 2006). Não houve perguntas de contestação, ou seja, perguntas que desafiassem a estrutura explicativa proposta pelo professor.

$\mathrm{Na}$ Tabela 3, são apresentados os percentuais relativos ao número de perguntas postas pelos alunos. Tais dados relacionam-se ao fato de que, à medida que o conteúdo do discurso evoluía em sala de aula, os alunos passavam a se envolver mais com o tema e com a dinâmica das aulas, o que os encorajava a utilizar as novas formas de expressão obtendo mais confiança e independência em seus discursos na perspectiva da ciência escolar (CANDELA, 1999). Desse modo, o número de questionamentos aumenta com o passar dos encontros. No encontro 1 houve poucas perguntas dos alunos. Consideramos que isso se deu devido aos alunos ainda estarem se familiarizando com a proposta de ensino e com os conteúdos abordados. O número de pergunta aumenta nos demais encontros, assumindo o valor máximo e igual nos encontros 3 e 4 .

Tabela 3 - Tipos de perguntas dos alunos

\begin{tabular}{llllll} 
Tipos de & \multicolumn{5}{c}{ Encontros } \\
\cline { 2 - 6 } perguntas & $\mathbf{1}$ & $\mathbf{2}$ & 3 & 4 & TOTAL \\
\hline $\begin{array}{l}\text { Perguntas de } \\
\begin{array}{l}\text { Esclarecimento } \\
\text { ou Extensão }\end{array}\end{array}$ & $33,33 \%(1)$ & $77,78 \%(7)$ & $80,00 \%(8)$ & $80,00 \%(8)$ & $75 \%(24)$ \\
\hline $\begin{array}{l}\text { Perguntas de } \\
\text { Extrapolação }\end{array}$ & $66,67 \%(2)$ & $22,22 \%(2)$ & $20,00 \%(2)$ & $20,00 \%(2)$ & $25 \%(8)$ \\
\hline TOTAL & $100 \%(3)$ & $100 \%(9)$ & $100 \%(10)$ & $100 \%(10)$ & $100 \%(32)$ \\
\hline
\end{tabular}

Fonte: Autoria própria (2017).

As perguntas dos alunos expressam o seu envolvimento no fluxo discursivo da sala de aula, uma mudança na estrutura das interações e, ainda, em algum nível, no foco do conteúdo, já que houve perguntas de extrapolação, ou seja, aquelas que potencialmente geram informações que estão além da lógica proposta pela estrutura explicativa do professor, alterando, também, o tema em discussão.

Abaixo apresentamos alguns exemplos de perguntas de esclarecimento e de extrapolação:

Esclarecimento:

Aluno 1 - Tem algum órgão que monitora a água mineral pra falar se ela... porquê a senhora disse que toda água é mineral, mas nem toda água é potável.

Aluno 11 - Professora, o pH pode variar com a temperatura da água?

Extrapolação:

Aluno 1 - E o pH do sangue precisa ser medido também? 
Aluno X - Professora, para medir a glicemia se usa um papel parecido com esse ((papel indicador)), não é? Como é que sabe se não tá bem?

Em todos os encontros, o número de perguntas de esclarecimento é maior que o de extrapolação. Nessa perspectiva, percebe-se que os encontros apresentam um mesmo padrão de posicionamento dos alunos diante do tema estudado, qual seja: o foco das atenções esteve em buscar compreender o tema, extrapolando menos os limites previstos. Consideramos que o fato de as aulas serem desenvolvidas sempre como referência a HQ, contribuiu para gerar discussões mais delimitadas por seu conteúdo, evitando muitas extrapolações.

Todavia, há que se analisar mais detidamente essa relação entre perguntas de esclarecimento e extrapolação. Não é de se estranhar que perguntas de extrapolação não ultrapassem as de esclarecimento nas aulas. Ainda que isso possa ocorrer em certas situações, em função da natureza da atividade desenvolvida, é compreensível que os alunos busquem se apropriar do conteúdo antes de ampliar o olhar para novas relações deste em outras situações. Isso guarda em si um aspecto positivo, considerando-se que a manutenção no foco sobre o tema proposto possibilita que ele seja melhor explorado.

Candela (1999) discute sobre as questões propostas pelos alunos em aulas de ciências considerando as assimetrias de poder que caracterizam as interações, sobretudo aquelas que se manifestam em ambientes institucionais, como é o caso do ambiente escolar. Nessa perspectiva, o clássico padrão I-R-A (iniciação do professor-Resposta do aluno-Avaliação do professor), característico das salas de aula, representa a assimetria de poder professor-aluno, considerando que o professor inicia o tema, propõe as perguntas e avalia as respostas obtidas. Algumas perguntas dos alunos, todavia, podem ser percebidas como intervenções que rompem um fluxo discursivo centrado no professor. Isso ocorre quando as questões mudam o rumo em que o conteúdo está sendo tratado ou planejado. Portanto, em certas situações, altera-se a assimetria de poder manifestada na interação, que passa do docente ao aluno, em termos de conteúdo conversacional e dinâmica interacional. Em tais situações, as perguntas dos alunos passam a ser cada vez mais autênticas e não há garantias de que o professor sempre terá as respostas solicitadas.

Considerando as categorias usadas em nossa análise, isso acontece quando ocorrem as perguntas de extrapolação e contestação. Assim, temos que $25 \%$ das perguntas dos alunos cumpriram o papel de gerar discussões não previstas pelo professor, rompendo também, nestes momentos, com um padrão interativo tradicional, em que o professor abre e fecha a cadeia de interação.

É relevante pontuar, ainda, que independentemente do tipo, o número de perguntas elaboradas pelos alunos em nossa pesquisa (32) expressa, em certo nível, o rompimento com o padrão triádico I-R-A (Iniciação do professorResposta do aluno - Avaliação do professor) (MEHAN, 1979), já que, na maioria das situações, o aluno passa a iniciar a cadeia de interação. Nesse sentido, voltar a atenção para as perguntas feitas pelos alunos significa ter a percepção de diferentes padrões interacionais que emergem ao longo das discussões e que, representa uma postura de um aluno com mais controle na interação com o professor. 


\section{O ENGAJAMENTO DISCIPLINAR PRODUTIVO DOS ALUNOS REFERENTE AOS ENCONTROS DA SEA}

Para análise acerca do engajamento disciplinar produtivo dos alunos referente aos encontros $1,2,3,4$, foi utilizado um gravador de áudio o qual foi anexado em um grupo de alunos diferente em cada encontro. O propósito foi verificar em quanto tempo esses alunos estavam engajados em discussões acerca dos conteúdos previstos e em quanto tempo estavam dispersos, abordando outros temas.

A Tabela 4 apresenta os percentuais de tempo de engajamento e de dispersão dos alunos para cada encontro.

Tabela 4 - Percentuais de tempo de engajamento e de dispersão dos alunos ao longo da SEA

\begin{tabular}{llll} 
Encontros & $\begin{array}{l}\text { Tempo de } \\
\text { Dispersão } \\
\text { (h:min:s) }\end{array}$ & $\begin{array}{l}\text { Tempo de } \\
\text { Engajamento } \\
\text { (h:min:s) }\end{array}$ & $\begin{array}{l}\text { Tempo total } \\
\text { (h:min:s) }\end{array}$ \\
\hline Encontro 1 (Aulas:1,2,3) & $00: 32: 00$ & $01: 06: 00$ & $01: 38: 00$ \\
\hline Encontro 2 (Aulas:4,5,6) & $00: 25: 10$ & $01: 17: 19$ & $01: 42: 29$ \\
\hline Encontro 3 (Aulas:7,8,9) & $00: 45: 00$ & $01: 47: 15$ & $02: 32: 15$ \\
\hline Encontro 4 (Aulas:10,11,12) & $00: 20: 10$ & $00: 53: 25$ & $01: 13: 35$ \\
\hline Total: & $02: 02: 20$ & $05: 03: 59$ & $07: 06: 19$ \\
\hline Percentual \% & $28,7 \%$ & $71,4 \%$ & $100 \%$ \\
\hline
\end{tabular}

Fonte: Autoria própria (2017).

Da análise dos encontros quanto ao engajamento dos alunos, verificamos que estes passaram a maior parte do tempo engajados $(71,4 \%)$, enquanto que em $28,7 \%$ (vinte e oito vírgula sete por cento) do tempo dos encontros os alunos passaram dispersos ou pouco envolvidos. Consideramos tal resultado favorável, e isto se deu tendo-se em vista o apelo da $\mathrm{HQ}$ e a abertura às discussões que foram realizadas em torno deste material. À medida que a leitura era feita, a professora intervinha expondo conceitos ou promovendo discussões. Entendemos ter havido engajamento disciplinar produtivo, visto que a medida que as interações discursivas ocorreram, novas questões foram trazidas pelos alunos na discussão sobre os conteúdos abordados na $\mathrm{HQ}$, além de estarem na maior parte do tempo em que interagiam com a $\mathrm{HQ}$, envolvidos no tema proposto pela professora (SASSERON; DUSCHL, 2016).

Fazendo uma análise mais detalhada acerca dos tempos de dispersão e de engajamentos para os encontros, percebemos que os alunos passaram mais tempo dispersos nos encontros 1 e 3 . Isso pode ter ocorrido porque no encontro 1 os alunos estavam se ambientando com a temática da SEA, sendo levados à problematização inicial. Já para o encontro 3 , essa dispersão pode ser justificada pela ocorrência da atividade investigativa envolvendo experimento. De acordo com dados disponíveis na literatura (SILVA, 2008; MORTIMER et al., 2007), as atividades práticas envolvendo experimentos tendem a gerar mais momentos de dispersão que aquelas desenvolvidas em sala de aula regular, pois além de os alunos estarem menos guiados pelo professor, costumam dispersar quando se passa de um procedimento a outro, o que acaba demandando mais tempo em 


\section{CONSIDERAÇÕES FINAIS}

Na pesquisa que aqui apresentamos, descrevemos a aplicação de uma SEA envolvendo $\mathrm{HQ}$ como recurso didático, de modo a verificar as interações discursivas que ocorreram em sala de aula e o engajamento dos alunos. Os resultados apontam para o potencial favorecedor do uso da HQ nesse sentido.

Tendo em vista os dados relativos aos tempos de engajamento dos alunos com o tema proposto na $\mathrm{HQ}$, bem como o número de perguntas apresentadas nos momentos de discussão com toda a turma, entendemos que este material didático proporcionou condições fundamentais para a aprendizagem de conceitos, uma vez que favoreceu a articulação de ideias no plano social da sala de aula. A estratégia de aplicação de uma SEA atrelada a uma HQ mobilizou os alunos para a aprendizagem de conceitos em torno da temática "qualidade da água".

Levando em conta os tipos de perguntas formuladas pelos alunos, consideramos relevante verificar, em pesquisas futuras envolvendo o uso da $\mathrm{HQ}$, a ocorrência de perguntas de extrapolação e mesmo de contestação, uma vez que uma hipótese para o baixo percentual da primeira e inexistência da segunda é o fato de que a dinâmica das aulas centradas neste material tenha acentuado os limites do tema para discussão.

Ressaltamos, todavia, que somente a leitura da $\mathrm{HQ}$ não promoveria as interações na sala de aula. A professora foi responsável por explorar o potencial deste material didático a fim de gerar espaços que conduziram os alunos a exporem seus pontos de vista e suas interpretações, nos momentos das discussões posteriores à leitura.

Embora a área de Educação em Ciências esteja em ascensão no que se refere a novas metodologias que se propõem ao desenvolvimento de materiais didáticos que auxiliem na construção dos conhecimentos científicos, se faz necessário avanços em pesquisas voltadas a análise desses materiais focando as interações promovidas e o engajamento dos alunos, entendendo-os como aspectos fundamentais para a construção do conhecimento em sala de aula. A pesquisa que aqui apresentamos buscou contribuir nessa direção. 


\title{
Using comic strips to mobilize discursive interactions in a teaching-learning sequence in chemistry
}

\begin{abstract}
This paper discusses the contributions of using chemistry comic strips in a teaching and learning sequence (TLS) to promote discursive interactions and student engagement. TLS was used in a workshop with 27 freshmen attending high school in a public educational institution. The written data and video-recorded classes were assessed through categories available in the literature. Such assessment focused on interaction patterns, kinds of questions asked by the students, and the degree of student engagement, considered essential elements to learning, according to a sociocultural perspective on education. The research is justified in view of the importance of investments in understanding the potential of didactical resources in science education, which promote social interactions in the classroom. The results indicate that comics used in TLS contributed to foster discussions on the proposed topic, "quality of water", through which it was possible to verify the students' engagement.
\end{abstract}

KEYWORDS: Comics. Teaching-Learning Sequence. Student engagement. 


\section{NOTAS}

1. Uma sequência triádica corresponde ao padrão de interação identificado por Mehan (1979) como I-R-A (Iniciação do professor- Resposta do aluno - Avaliação do professor) e por Sincalir e Coultard (1975) como I-R-F (Iniciação do professorResposta do aluno - Follow-up, entendido como Feedback ou Prosseguimento pelo professor). A avaliação (A) constitui-se no terceiro turno da tríade, na proposta de Mehan (1979).

2. Uma cadeia fechada de interação, por sua vez, pode envolver várias tríades, com algumas alterações no padrão, mas, por ser fechada, finaliza-se sempre com a avaliação pelo professor (A).

3. Todos os 27 alunos participantes da SEA apresentaram, por meio do TCLE (Termo de Consentimento Livre e Esclarecido), seu consentimento para uso dos registros escritos e em vídeo para os fins da pesquisa, desde que suas identidades fossem preservadas.

4. A HQ pode ser acessada no link http://ri.ufs.br/jspui/handle/riufs/8301 como anexo da dissertação da primeira autora deste artigo.

\section{AGRADECIMENTOS}

Agradecemos à Capes pelo apoio financeiro.

\section{REFERÊNCIAS}

AGUIAR, O. G.; MORTIMER, E. F.; SCOTT, P. As perguntas dos estudantes e seus desdobramentos no discurso das salas de aula de ciências. In: X Encontro de Pesquisa em Ensino de Física, 10., 2006, Londrina. Anais do X EPEF. Londrina: Sociedade Brasileira de Fisica, 2006. p. 1-13. v. 1 (cd-rom).

AGUIAR JUNIOR. O. G.; MORTIMER, E. F. Tomada de consciência de conflitos: análise da atividade Discursiva em uma Aula de Ciências. Investigações em Ensino de Ciências, Porto Alegre, v. 10, n. 2, p. 179-207, 2005.

AULER, D. Alfabetização científico-tecnológica: um novo "paradigma". Ensaio Pesquisa em Educação em Ciências, Belo Horizonte, v. 5, n. 1, p. 1-16, 2003.

BEGO, A. M.; ALVES, M.; GIORDAN, M. O planejamento de sequências didáticas de química fundamentadas no Modelo Topológico de Ensino: potencialidades do Processo EAR (Elaboração, Aplicação e Reelaboração) para a formação inicial de professores. Ciência \& Educação, Bauru, v. 25, n. 3, p. 625-645, 2019.

BRASIL. Ministério da Educação. Parâmetros Curriculares Nacionais: Ensino Médio: Ciências da natureza, matemática e suas tecnologias. Brasília: MEC/SEMTEC. 58 p., 2002. 1996. Lex: legislação federal: edição federal, Brasília, v. s/n, 2005. 
CAMARGO, S. C.; RIVELINI-SILVA, A. C. História em quadrinhos no ensino de ciências: um olhar sobre o que já foi produzido nos últimos doze anos no ENEQ e ENPEC. ACTIO, Curitiba, v. 2, n. 3, p. 133-150, 2017.

CANDELA, A. Ciência en la aula: los alumnos entre la argumentacion y el consenso. Ciudad de Mexico: Paidos Educador 1999.

CARVALHO, A. M. P de. O ensino de ciências e a proposição de sequências de ensino investigativas. In: CARVALHO, A. M. P de (Org.). Ensino de ciências por investigação: condições para implementação em sala de aula. São Paulo: Cengage Learning, 2013, p. 1-20.

DELIZOICOV, D.; ANGOTTI, J. A.; PERNAMBUCO, M. M. Ensino de ciências: fundamentos e métodos. 2 ed. São Paulo: Cortez, 2002.

GUIMARÃES, Y. A. F. E.; GIORDAN, M. Instrumento para construção e validação de sequências didáticas em um curso a distância de formação continuada de professores. In: VIII Encontro Nacional de Pesquisa em Educação em Ciências, 8., 2012, Campinas. Atas [...]. Campinas: ABRAPEC, 2012. p. 3-13.

KELLY, G. J. Inquiry, activity and epistemic practice. In: DUSCHL, R. A.; GRANDY, R. E. (eds.). Teaching Scientific Inquiry: recommendations for research and implementation. Rotterdam: Taipei Sense Publishers, 2008. p. 288-291.

LÉVY, P. Cibercultura. Trad. Carlos I. da Costa. São Paulo: Ed. 34, 1999.

LUYTEN, S. M. B. Quadrinhos na sala de aula. In: TV ESCOLA/SALTO PARA O FUTURO (Org.). História em quadrinhos: um recurso de aprendizagem, Ano XXI Boletim 01. Brasília: Tv Escola, 2011. p. 21-26.

MEHAN, H. Learning lessons: social organization in theclassroom. Cambridge, MA: University Press, 1979.

MORTIMER, E.; MASSICAME, T.; BUTY, C.; TIBERGHIEN, A. Uma metodologia para caracterizar os gêneros de discurso como tipos de estratégias enunciativas nas aulas de ciências. In: NARDI, R. A pesquisa em ensino de ciência no Brasil: alguns recortes. São Paulo: Escrituras, 2007, p. 53-94.

MORTIMER. E. F.; SCOTT, P. H. Meaning making in secondary science classroom. Maidenhead: Open University Press/ McGraw Hill Education, 2003.

SANTOS, J. S.; GUEDES, J. T.; OLIVEIRA, F. S.; SANTOS, L. D. S.; CRUZ, M. C. P. Abordagem do comportamento ácido e básico nas frutas através das Histórias em Quadrinhos (HQs). In: XVII Encontro Nacional de Ensino de Química, 2014, Ouro Preto. Anais [...]. Ouro Preto: Sociedade Brasileira de Química, 2014. p. 1-11.

SANTOS, J. S.; SILVA, A. C. T.; OLIVEIRA, F. S. Histórias em Quadrinhos no ensino de Química: o que tem sido produzido em revistas e eventos da área na última década. In: XVIII Encontro Nacional de Ensino de Química, 2016, Florianópolis, 
SASSERON, L. H.; DUSCHL, R. A. Ensino de ciências as práticas epistêmicas: o papel do professor e o engajamento dos estudantes. Investigações em Ensino de Ciências, Porto Alegre, v. 21, n. 2, p. 52-67, 2016.

SILVA, A. C. T. Estratégias enunciativas em salas de aula de química: contrastando professores de estilos diferentes. 2008. Tese (Doutorado em Educação, UFMG) - Faculdade de Educação Universidade Federal de Minas Gerais, Belo Horizonte, 2008.

SOARES NETO, F. F.; PEREIRA, P. B. E.; SOUZA, C. A. Conceitos científicos nas histórias em quadrinhos: possibilidades e desafios para um processo de textualização. In: IX Encontro Nacional de Pesquisa em Educação em Ciências - I, 2013, Águas de Lindóia. Atas [...]. Águas de Lindóia: ABRAPEC, 2013. p. 1-8.

VERGUEIRO, W. As histórias em 10 quadrinhos. Folha de S. Paulo, São Paulo, 2004.

VERGUEIRO, W. Histórias em quadrinhos e serviços de informação: um relacionamento em fase de definição. Data Grama Zero, v. 6, n. 2, p. 1-13, 2005.

Recebido: 28 jul. 2020

Aprovado: 24 ago. 2020

DOI: $10.3895 /$ actio.v5n3.11391

Como citar:

SANTOS, J. S.; OLIVEIRA, F. S. de.; SILVA, A. da C. T. e. Uma história em quadrinhos para mobilizar as interações discursivas em uma sequência de ensino e aprendizagem de Química. ACTIO, Curitiba, v. 5, n. 3, p. 1-24, set./dez. 2020. Disponível em: <https://periodicos.utfpr.edu.br/actio>. Acesso em: $\mathrm{XXX}$

Correspondência:

Jucilene Santana Santos

Travessa Adauto Botelho, n. 62, Getúlio Vargas, Aracaju, Sergipe, Brasil.

Direito autoral: Este artigo está licenciado sob os termos da Licença Creative Commons-Atribuição 4.0 Internacional.

(c) (i) 